\title{
SEISMIC RETROFITTING OF AN EXISTING STRUCTURE
}

\author{
Amritha Ranganadhan ${ }^{1}$, Anju Paul ${ }^{2}$ \\ ${ }^{1}$ M.Tech Student, Dept. of Civil Engineering, TIST Arakkunnam \\ ${ }^{2}$ Assistant Professor, Dept. of Civil Engineering, TIST Arakkunnam
}

\begin{abstract}
Retrofitting an existing building is often considered to be more cost-effective than constructing a new building. It represents an opportunity to upgrade the overall performance, sustainability and efficiency of an existing building. Seismic retrofitting is mainly done to provide existing structures with more resistance to seismic activity due to earthquake. Earthquake creates great devastation in terms of life, money and failure of structures. Therefore, increasing the seismic resistance of structures is of utmost importance, especially in case of old structures, and tall or expensive structures. When a building has been designed according to a seismic code, but the code has been upgraded in the later years, it results in deficiencies to exist in design or construction of the structure. In Kerala, there exist several old buildings which were designed for seismic zone II, whereas, at present Kerala belongs to seismic zone III. In this paper, a building that was designed for seismic zone II is selected. The analysis of the structure is carried out and the structure is redesigned for seismic zone III. The additional seismic resistance required for the structure is determined and retrofitting methods are proposed to achieve the required seismic strength.
\end{abstract}

Keywords-retrofitting; design; CFRP

\section{INTRODUCTION}

Seismic retrofitting is mainly done to meet the seismic safety requirements. The planning of alterations to existing buildings differs from new planning through an important condition; the existing construction must be taken as the basis of all planning and building actions. India is one of the most earthquake prone countries in the world and has experienced several major or moderate earthquakes during the last 15 years. About 50-60\% of the total area of the country is vulnerable to seismic activity of varying intensities. Many existing buildings do not meet the seismic strength requirement. The need for seismic retrofitting of an existing building can arise due to several reasons like: building not designed to code, subsequent updating of code and design practice, subsequent upgrading of seismic zone, deterioration of strength and aging, modification of existing structure, change in use of the building, etc. Seismic retrofit is primarily applied to achieve public safety, with various levels of structure and material survivability determined by economic considerations. In recent years, an increased urgency has been felt to strengthen the deficient buildings, as part of active disaster mitigation, and to work out the modifications that may be made to an existing structure to improve the structural performance during an earthquake.

\section{BACKGROUND OF WORK}

\subsection{General}

Aryabhata Block of Toc $\mathrm{H}$ Institute of Science And Technology is the building selected for the study. It is located in Arakkunnam. Aryabhata Block is a $B+G+3$ building. The plan of the building is drawn in such a way that it has fulfilled all the required facilities. The building consists of class rooms, laboratories, offices, faculty rooms, seminar hall, library, toilet, canteen, lift etc.

\subsection{Features of the College Building}

i. Total plinth area $=6450.91 \mathrm{~m}^{2}$

ii. Plinth area of basement floor $=937.26 \mathrm{~m}^{2}$

iii. Plinth area of ground floor $=1483.32 \mathrm{~m}^{2}$

iv. Plinth area of $1 \mathrm{st}$ floor $=1335.40 \mathrm{~m}^{2}$

v. Plinth area of 2 nd floor $=1483.32 \mathrm{~m}^{2}$

vi. Plinth area of 3rd floor $=1211.61 \mathrm{~m}^{2}$

vii. Height of building $=19.5 \mathrm{~m}$

\section{MODELLING AND ANALYSIS}

The structural modeling and analysis of the building is performed using STAAD PRO. Abbreviations and Acronyms

\subsection{Model}

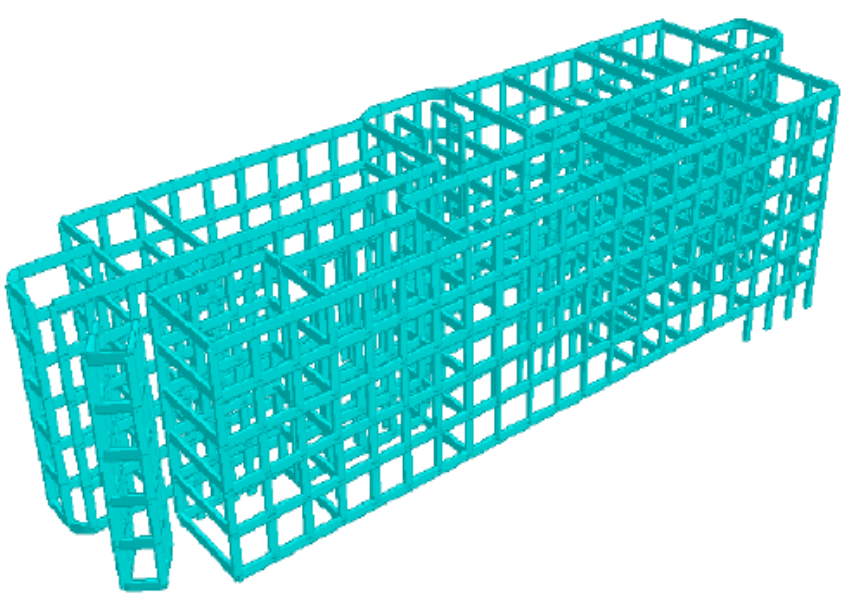




\subsection{Analysis Results}

Detailed analysis is done both manually and using the software STAAD PRO based on the codes IS 1893-1984 for the seismic zone II as well as IS 1893-2002 for the seismic zone III. The seismic weight of the building calculated manually is obtained as $70017.605 \mathrm{kN}$ and from software is $76002.6 \mathrm{kN}$. The results obtained from manual calculations and software analysis was found to be comparable. Ah value for zone II is obtained as 0.0625 and that for zone III is obtained as 0.1 . Thus, there is a $60 \%$ increase in Ah value.

\section{STRUCTURAL DESIDN}

Limit state method is followed for the design of Reinforced concrete elements. The design of structural elements such as slabs, beams, lintel, columns and staircase are done. The sample calculations for the design of all the structural elements are given in the following pages.

\subsection{Design of Beam for Zone II and III}

Use $\mathrm{M}_{20}$ grade concrete and HYSD steel bars of grade $\mathrm{Fe}_{415}$

Width of the beam $=300 \mathrm{~mm}$

Depth of the beam $=800 \mathrm{~mm}$

Assume $25 \mathrm{~mm}$ clear cover and $20 \mathrm{~mm} \phi$ bars

Effective depth $=765 \mathrm{~mm}$

Ultimate bending moment, $\mathrm{M}_{\mathrm{u}}=333.902 \mathrm{kNm}$ (from STAAD)

Ultimate shear force, $\mathrm{V}_{\mathrm{u}}=177.327 \mathrm{kN}$ (from STAAD)

$\left(\mathrm{M}_{\mathrm{u}}\right) \lim =484 \mathrm{kNm}$

$\mathrm{M}_{\mathrm{u}}<\left(\mathrm{M}_{\mathrm{u}}\right)$ lim, Hence design as singly reinforced section

Main Reinforcement:

From SP16 table 2, $\mathrm{P}_{\mathrm{t}} \%=0.602$

$\mathrm{A}_{\mathrm{st}}($ required $)=1444.8 \mathrm{~mm} 2$

Taking 2 nos of $20 \mathrm{~mm} \phi$ bars and 2 nos of $25 \mathrm{~mm} \phi$ bars, $\mathrm{A}_{\mathrm{st}}($ required $)=1610.04 \mathrm{~mm}^{2}$

Table 1: reinforcement details of beam

\begin{tabular}{|c|c|c|r|c|}
\hline Location & $\mathrm{M}_{\mathrm{u}}$ & $\begin{array}{c}\mathrm{A}_{\text {st }} \\
\text { (required) }\end{array}$ & Bars & $\begin{array}{c}\mathrm{A}_{\mathrm{st}} \\
\text { (provided) }\end{array}$ \\
\hline Support & 333.902 & $1444.8 \mathrm{~mm}^{2}$ & $2-20 \phi$ & $\begin{array}{c}1610.04 \mathrm{~m} \\
\mathrm{~m}^{2} \\
2-25 \phi\end{array}$ \\
\hline Midspan & 126.731 & $676 \mathrm{~mm}^{2}$ & $3-20 \phi$ & $\begin{array}{c}942.45 \\
\mathrm{~mm}^{2}\end{array}$ \\
& & & & \\
\hline
\end{tabular}

Detailing:
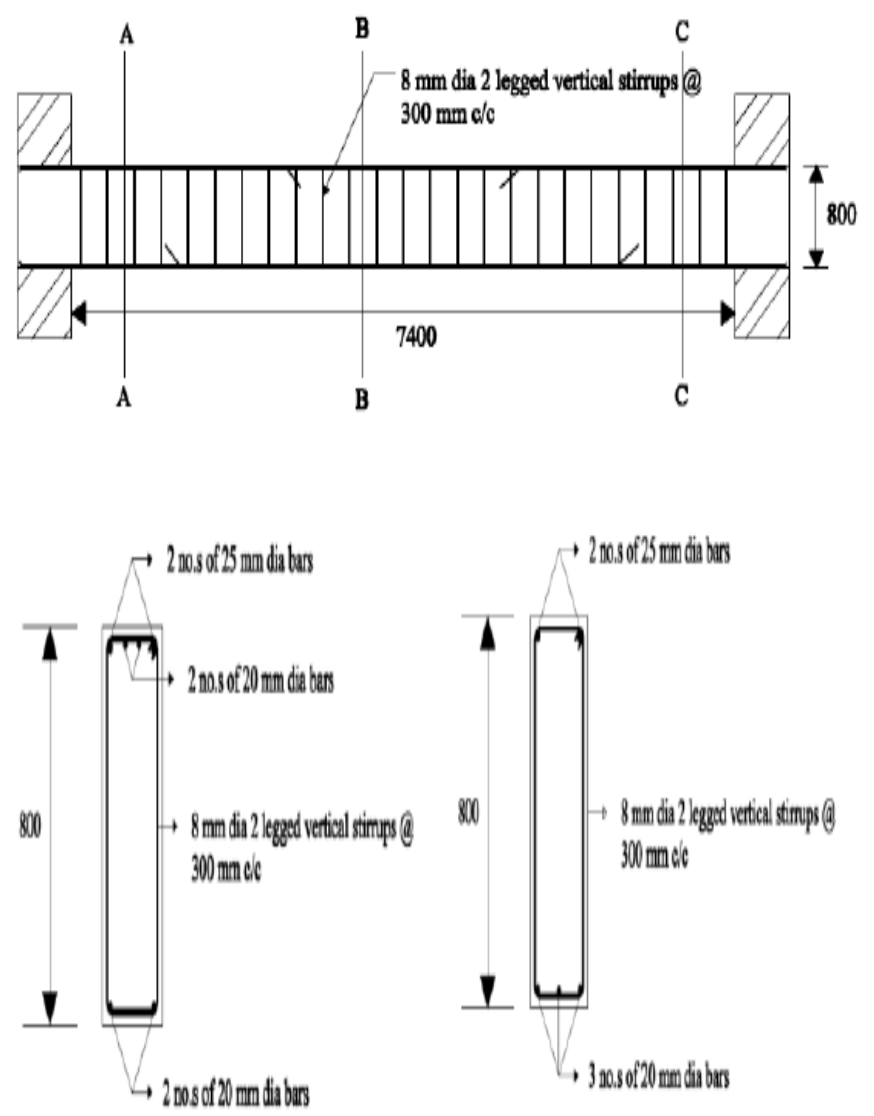

Fig. 1 Detailing of beam

Even for zone III, the design obtained is the same.

\subsection{Design of Two Way Slab}

Centre to centre distance of longer span $=9.2 \mathrm{~m}$ Centre to centre distance of shorter span $=5.55 \mathrm{~m}$ Ratio of long span to short span $=9.2 / 5.55=1.65<2$ Type of slab: four edges continuous.

Table 2: reinforcement details of two way slab

\begin{tabular}{|c|c|c|c|}
\hline Location & $\mathrm{A}_{\text {st }}$ (required) & $\begin{array}{l}\text { Spacing of } \\
8 \mathrm{~mm} \phi \text { bars }\end{array}$ & $\mathrm{A}_{\mathrm{st}}($ provided $)$ \\
\hline \multicolumn{4}{|l|}{ 1)short span } \\
\hline $\begin{array}{l}\text { BM(top of } \\
\text { supports) } \\
\text { +ve }\end{array}$ & $439.58 \mathrm{~mm}^{2}$ & $110 \mathrm{~mm}$ & $456.9 \mathrm{~mm}^{2}$ \\
\hline $\begin{array}{l}\text { BM(centre of } \\
\text { span) }\end{array}$ & $328.24 \mathrm{~mm}^{2}$ & $150 \mathrm{~mm}$ & $335.06 \mathrm{~mm}^{2}$ \\
\hline \multicolumn{4}{|l|}{ 2)long span } \\
\hline -ve & $21990 \mathrm{~mm}^{2}$ & $220 \mathrm{~mm}$ & $22845 \mathrm{~mm}^{2}$ \\
\hline supports) & & & \\
\hline $\begin{array}{l}\mathrm{BM} \text { (centre of } \\
\text { span) }\end{array}$ & $216 \mathrm{~mm}^{2}$ & $230 \mathrm{~mm}$ & $218.52 \mathrm{~mm}^{2}$ \\
\hline
\end{tabular}


Detailing:
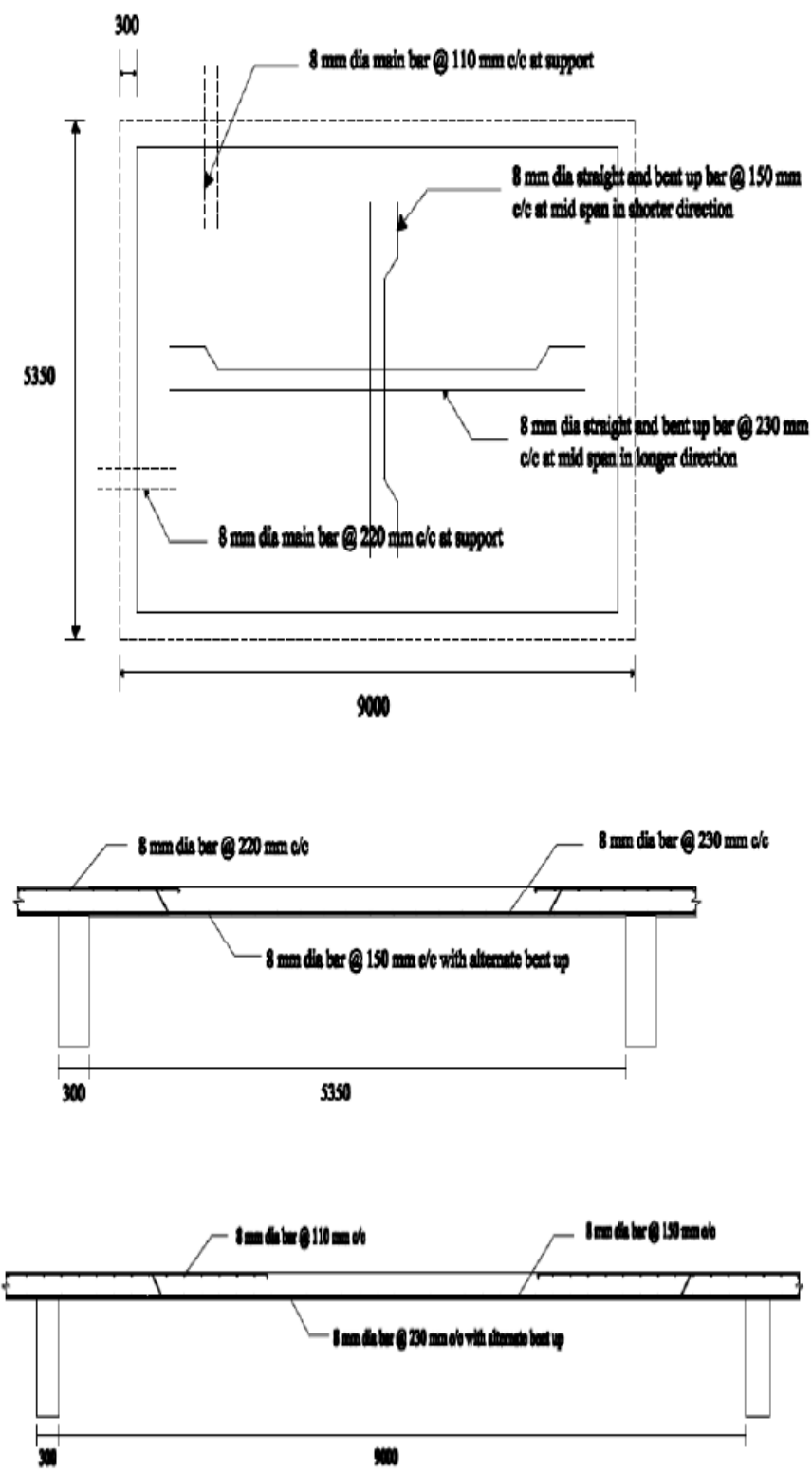

Fig. 2 Detailing of two way slab

\subsection{Design of One Way Slab}

Dimension $=3 \times 8 \mathrm{~m}$

Ratio of long span to short span $=8 / 3=2.67>2$

Area of steel required $=232.55 \mathrm{~mm}^{2}$

Provide $8 \mathrm{~mm} \Phi$ bars @ $210 \mathrm{~mm}$ c/c.

Area of distribution steel $=192 \mathrm{~mm}$

Provide 8mm $\Phi$ bars $260 @$ mm c/c.
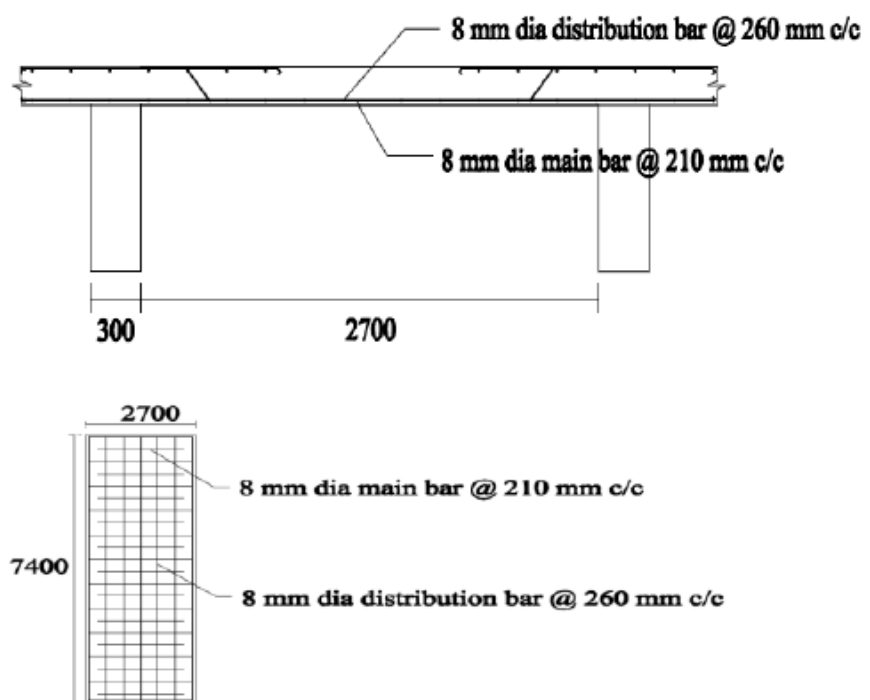

Fig. 3 Detailing of one way slab

\subsection{Design of Rectangular Column for Zone II}

Depth of column, $\mathrm{D}=600 \mathrm{~mm}$

Breadth of column, $b=300 \mathrm{~mm}$

Support condition is one end fixed and other hinged.

Ast $=3600 \mathrm{~mm}^{2}$

Provide 8 numbers of $25 \mathrm{~mm} \phi$ bars distributed equally on four sides.

Provide $8 \mathrm{~mm}$ lateral ties at $300 \mathrm{~mm} \mathrm{c} / \mathrm{c}$.
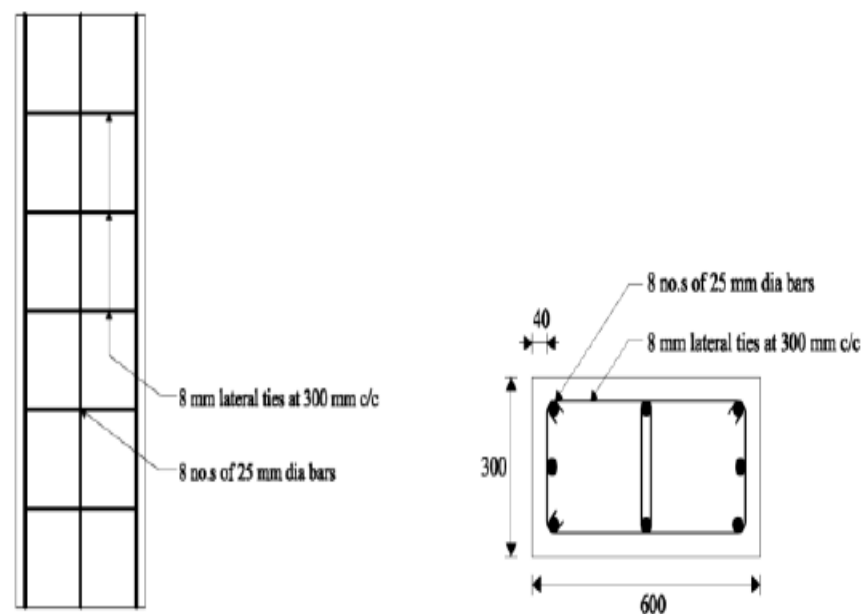

Fig. 4 Detailing of rectangular column (zone II)

\subsection{Redesigning of Rectangular Column for Zone}

III

Depth of column, $\mathrm{D}=600 \mathrm{~mm}$

Breadth of column, $b=300 \mathrm{~mm}$

Support condition is one end fixed and other hinged.

Ast $=5400 \mathrm{~mm}^{2}$

Provide 12 numbers of $25 \mathrm{~mm} \phi$ bars distributed equally on four sides.

Provide $8 \mathrm{~mm}$ lateral ties at $300 \mathrm{~mm} \mathrm{c} / \mathrm{c}$. 

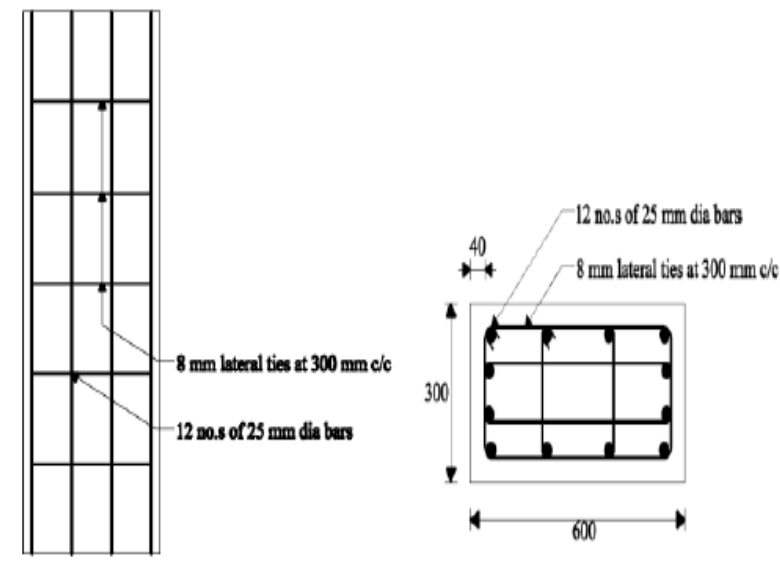

Fig. 5 Detailing of rectangular column (zone III)

\subsection{Design of Circular Column for Zone II}

Diameter of column, $\mathrm{D}=460 \mathrm{~mm}$

Support condition is one end fixed and other hinged. Ast $=2116 \mathrm{~mm} 2$

Provide 7 numbers of $20 \mathrm{~mm} \phi$ bars.

Provide $8 \mathrm{~mm} \phi$ bars at $300 \mathrm{~mm} \mathrm{c/c}$.

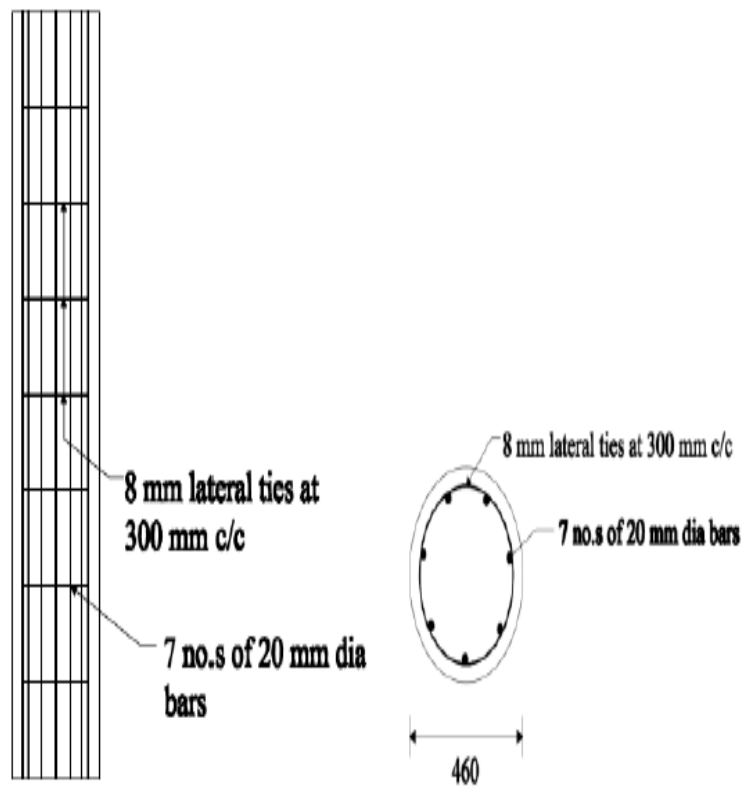

Fig. 6 Detailing of circular column (zone II)

\subsection{Redesigning of Circular Column for Zone III}

Diameter of column, $\mathrm{D}=460 \mathrm{~mm}$

Support condition is one end fixed and other hinged.

Ast $=4232 \mathrm{~mm}^{2}$

Provide 14 numbers of $20 \mathrm{~mm} \phi$ bars.

Provide $8 \mathrm{~mm} \phi$ bars at $300 \mathrm{~mm} \mathrm{c/c}$.

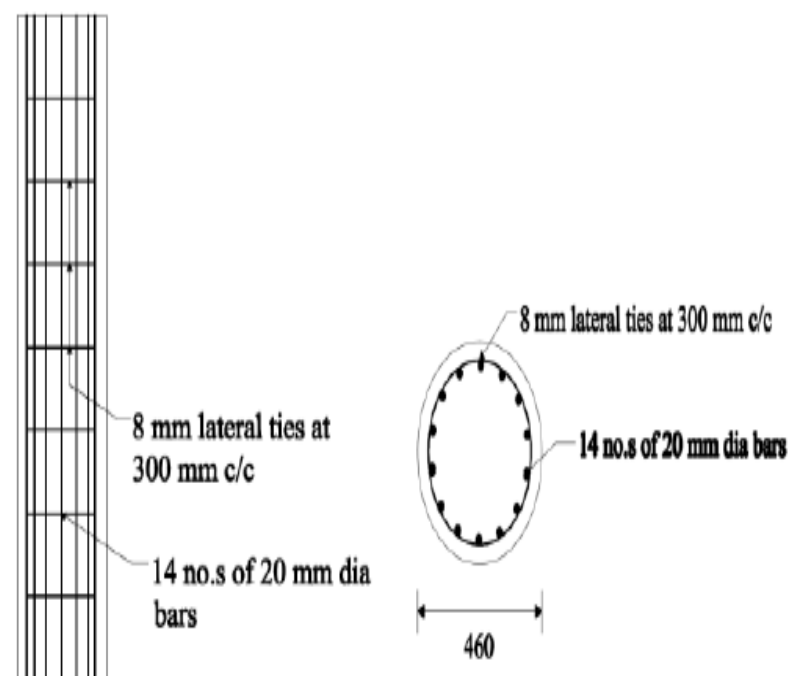

Fig. 7 Detailing of circular column (zone III)

\subsection{Design Of Lintel}

Support width $=250 \mathrm{~mm}$

Clear span $=2200 \mathrm{~mm}$

Ast $=101.54 \mathrm{~mm}^{2}$

Provide 3 nos of $8 \mathrm{~mm}$ dia bars as main reinforcement

Provide 2 nos of $8 \mathrm{~mm}$ dia bars as stirrup holder.

Provide 8 mm two legged stirrups @ $160 \mathrm{~mm} \mathrm{c} / \mathrm{c}$
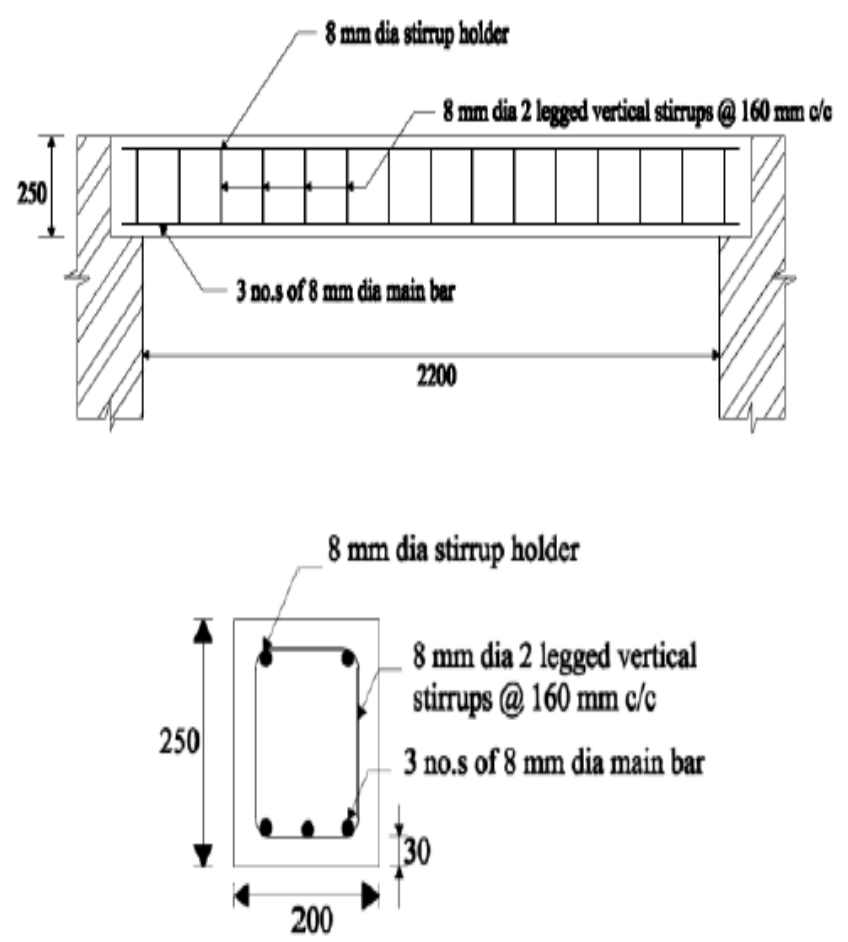

Fig. 8 Detailing of lintel

\subsection{Design of Staircase}

Width of stair $=4 \mathrm{~m}$

Rise $=150 \mathrm{~mm}$

Thread $=300 \mathrm{~mm}$

No of risers $=26$ 

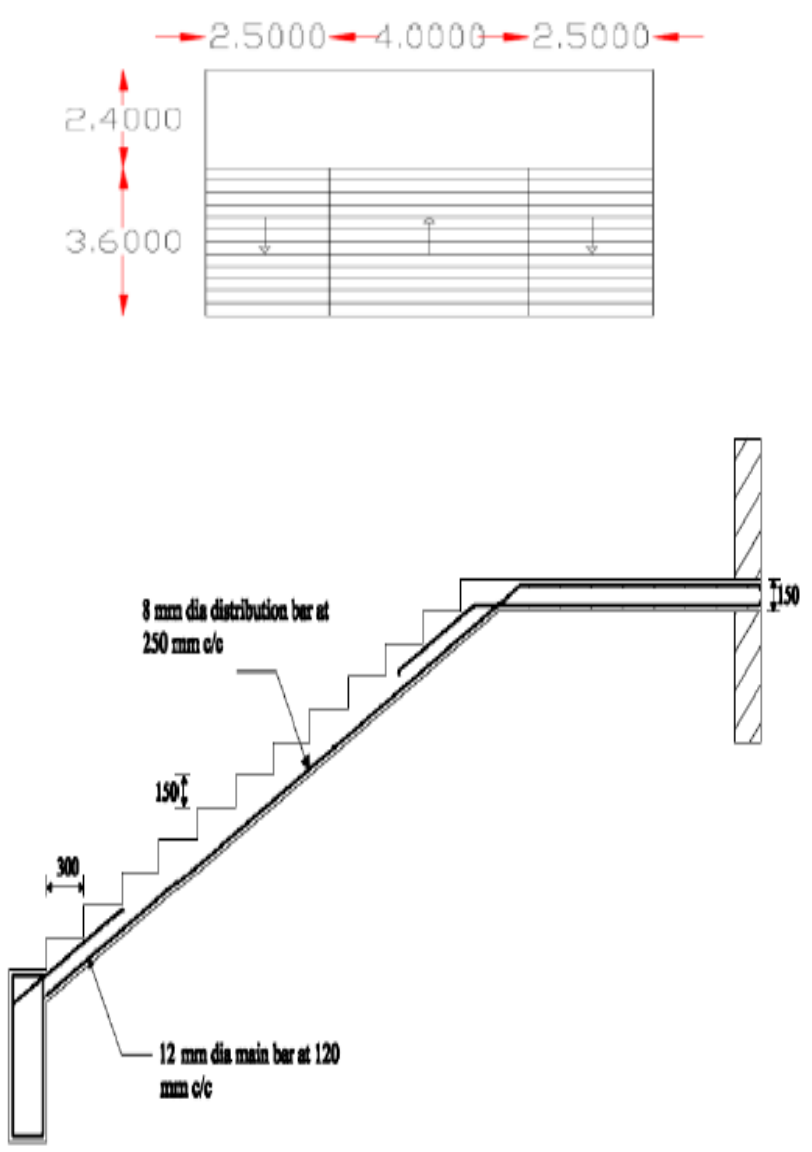

Fig. 9 Detailing of staircase

- Effect of seismic force was found to be more in columns.

- While redesigning, no. of bars obtained was more for columns.

\section{RETROFITTING OF COLUMNS}

It is not financially feasible to replace all deficient structures, and hence retrofitting of existing deficient structure is a necessary option. The ability of structures to achieve adequate deformation capacity plays a significant role in the prevention of structural failures in seismic events. Ductile structures dissipate more energy. The deformation capacity of existing structures can be enhanced by modifying certain substructure elements and connections. Columns are typically retrofitted to increase the overall ductility of the structure. Several retrofitting techniques such as reinforced concrete jacketing and steel jacketing have been developed to rehabilitate structurally-deficient columns. In the last decade or so, fiber reinforced polymers (FRP) have attracted the attention of researchers as an alternative material for retrofitting reinforced concrete elements. Compared to steel and concrete jacketing, FRP wrapping has several advantages, including extremely low weight-to-strength ratios, high elastic moduli, resistance to corrosion, and ease of application. In addition, unidirectional FRP wrapping can improve column ductility without considerable stiffness amplification. Commonly employed FRP composite materials are carbon fiber reinforced polymer (CFRP), glass fiber reinforced polymer (GFRP) and aramid fiber reinforced polymer (AFRP). Most FRP materials exhibit nearly linear elastic behavior up to failure. In general, CFRP has a higher modulus of elasticity than AFRP and GFRP. In terms of tensile strength, CFRP has the highest strength, followed by AFRP and GFRP. Despite GFRP's lower mechanical properties, it is preferable for many civil engineering applications due to its lower cost. FRP retrofit systems can be effective for both circular and rectangular columns. Circular jackets provide the column with a continuous confinement pressure, while rectangular jackets only provide confinement pressure at the corners.

\section{CONCLUSION}

This paper discusses the analysis and designing of an existing old structure which was actually designed for seismic zone II as per the previous code ie IS 1893: 1984 and redesigning the structure as per the revised code ie IS 1893: 2002 for seismic zone III. Columns are found to be the deficient member and are to be retrofitted so as to achieve ductile performance. The most suitable retrofitting technique ie use of FRP wrapping is suggested for the retrofitting of the deficient columns.

\section{REFERENCES}

[1] Anand S. Arya and Ankush Agarwal (2007), "Condition Assessment Of Buildings For Repair And Upgrading”, Disaster Risk Management Programme, pp. 1-16

[2] Caglar Goksu; Alper Polat and Alper Ilki (2012), "Attempt for Seismic Retrofit of Existing Substandard RC Members under Reversed Cyclic Flexural Effects", Journal Of Composites For Construction (C) ASCE, 16, pp.286-299

[3] Giuseppe Oliveto and Massimo Marletta (2005), "Seismic Retrofitting Of Reinforced Concrete Buildings Using Traditional And Innovative Techniques", ISET Journal of Earthquake Technology, 42(2), pp.21-46

[4] Loring A. Wyllie (1983), "Seismic strengthening procedures for existing structures", 46, pp.353-370

[5] Mariamol Kuriakose and Preetha Prabhakaran (2013), "Seismic Evaluation Of Existing Buildings In Karnataka", International Journal of Innovative Research in Science, Engineering and Technology, 2(1), pp. 107-115

[6] Minakshi V. Vaghani; Sandip A. Vasanwala and Atul K. Desai (2014), "Advanced Retrofitting Techniques for RC Building: A State of an Art Review", International Journal of Current Engineering and Technology, 4(2), pp. 579-584 